\title{
Clean Nitrations: Novel Syntheses of Nitramines and Nitrate Esters by Nitrodesilylation Reactions using Dinitrogen Pentoxide $\left(\mathrm{N}_{2} \mathrm{O}_{5}\right)^{1,2}$
}

\author{
Ross W. Millar* and Simon P. Philbin \\ Defence Research Agency, Fon Halstead, Sevenoaks, Kent TN14 7BP
}

\begin{abstract}
In this novel nitration method dinitrogen pentoxide $\left(\mathrm{N}_{2} \mathrm{O}_{5}\right)$ in an incrt solvent is used as the nitrating agent, thereby removing the need for strong acids as the reaction medium. The $\mathrm{N}_{2} \mathrm{O}_{5}$ cleaves heteroatom-silicon bonds, in silylamines and silyl ethers respectively, to yield the desired energetic groupings (nitramines or nitrate esters respectively) without liberation of acids which would occur with conventional substrates (amines or alcohols). These nitrodesilylation reactions proceed cleanly and in good yield, and the scope of the reaction is illustrated by 29 examples, some of which produce high energy compounds, notably plasticisers and an energetic polymer precursor. These reactions are therefore potentially clean nitrations for the manufacture of energetic compounds which will minimise the impact of this activity on the environment in the future.

(1) British Crown 1997. Defence Evaluation and Research Agency. Published by Elsevier Science Ltd.
\end{abstract}

\section{INTRODUCTION}

Nitramines and nitrate esters are classes of compounds which find widespread application in propellant and explosive technology ${ }^{3-5}$, and nitrate esters also find use in medicine as vasodilators ${ }^{6,7}$. The chemistry of each class of compound has been reviewed 8,9 . The preparation of these compounds by traditional routes requires the use of reagents, and generates by-products, which are in many cases unfriendly to the environment, requiring costly clean-up to avoid pollution. The aim of the work presented here is to find alternative routes which will produce the required nitramine and nitrate ester products with reduced impact on the environment.

Firstly the traditional routes will be considered before describing the chemistry involved in the novel routes, which employ nitrodesilylation chemistry. Finally the advantages in the novel chemistry will be assessed, particularly from the environmental point of view.

\section{Nitramines}

Nitramines are commonly prepared by the reaction of secondary amides with nitric acid in dehydrating media such as acetic anhydride ${ }^{10}$, although other routes are possible, for instance by the addition of nitrate salts of secondary amines to acetic anhydride in the presence of a catalyst, e.g. chloride ion 11 , by direct interaction of an amine with dinitrogen pentoxide, $\mathrm{N}_{2} \mathrm{O}_{5}{ }^{12}$, or by nitrolysis of gem-diamines with nitric acidacetic anhydride 13,14 . More recently developed methods include the reaction of $\mathrm{N}, \mathrm{N}$-dialkylamides with nitronium tetrafluoroborate ${ }^{15}$, the reaction of tert.-butylamines with nitric acid or $\mathrm{N}_{2} \mathrm{O}_{5}{ }^{16}$, and the action of nitric acid-acetic anhydride on tert. amines with in situ oxidation of the resulting nitrosamines with peracetic acid $^{17}$. 
Many of these routes have disadvantages such as contamination of the product by nitrosamines which are awkward to remove ${ }^{18}$, the use of reagents which are not available cheaply on an industrial scale (e.g. $\mathrm{NO}_{2} \mathrm{BF}_{4}$ ), or the production of co-products which are difficult to dispose of, notably acyl nitrates. Further problems may arise from inaccessibility of substrates: for instance in the direct nitration of amines ${ }^{12}$, certain categories of amine either do not form the nitramine (particularly highly basic amines), or may not be preparable in their unsubstituted form (e.g. hexahydropyrimidines - see later). Such shortcomings limit the scope and utility of existing routes for the synthesis of nitramines.

The problems outlined above are exemplified in one of the most commonly used routes for nitramine synthesis, namely the reaction of secondary amides with nitric acid under dehydrating conditions (Eqn. 1), where the cleavage of the $\mathrm{N}$-acyl bond results in formation of the desired nitramine (I), but an acyl nitrate coproduct (II) is also formed during the reaction (termed a nitrolysis ${ }^{10}$ ). The disposal of these acyl nitrates is

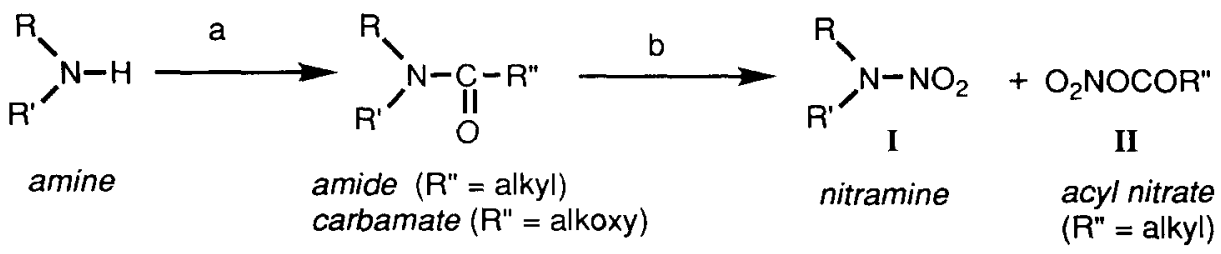

[Reagents:- a) acylating agent (eg R"COCl)

b) nitrating agent, esp. pure $\mathrm{HNO}_{3}, \mathrm{NO}_{2}{ }^{+} \mathrm{BF}_{4}{ }^{-}$or $\mathrm{N}_{2} \mathrm{O}_{5}$ ]

awkward and also poses safety problems in certain circumstances, for instance in the synthesis of HMX from DADN 19. A further drawback of the nitrolysis of acylamines is that cleavage of N-C bonds other than the acyl linkage may occur, resulting in competing reaction pathways and hence lower yields and product contamination, and in extreme cases little of the desired product may be formed (e.g. N,N-dimethylurethane (III) yields ethoxy $\mathrm{N}$-methyl- $\mathrm{N}$-nitrocarbamate (IV) instead of $\mathrm{N}, \mathrm{N}$-dimethylnitramine ${ }^{20}$ ). Finally, some acyl derivatives of polycyclic polyamines (e.g. the precursor of bicyclo-HMX, V) are completely inert to nitrolysis ${ }^{21}$.<smiles>CCOC(=O)N(C)C</smiles>

III<smiles>CCOC(=O)N(C)[N+](=O)[O-]</smiles>

IV<smiles>CC(=O)N1CN([N+](=O)[O-])C2C1N(C(C)=O)CN2[N+](=O)[O-]</smiles>

\section{Nitrate esters}

The majority of the methods reported ${ }^{9}$ for the synthesis of this class of compounds has relied on the use of mixed acids $\left(\mathrm{HNO}_{3}-\mathrm{H}_{2} \mathrm{SO}_{4}\right)$ or pure nitric acid, both of which media suffer from disposal problems of spent liquors which are unfriendly to the environment. These liquors are in some cases quite hazardous owing to the solubility of some nitrate esters in them (e.g. triethyleneglycol dinitrate shows $c a 9 \%$ vol./vol. solubility in spent $\mathrm{HNO}_{3}-\mathrm{H}_{2} \mathrm{SO}_{4}{ }^{22}$ ), and care is required in their handling and disposal. Furthermore, the solubility of certain nitrate esters in water can be problematic (e.g. ethyleneglycol dinitrate shows $c a 4 \%$ wt./vol. solubility 
in water ${ }^{23}$, a high figure for a covalent ester) and washing neat nitrate esters with water, as occurs in conventional processes, can lead to product loss and excessive contamination of wastewaters.

Some methods utilising transfer nitrating agents $9 \mathrm{~b}, 9 \mathrm{c}$ would appear to offer an escape from these problems until it is realised that nitronium tetrafluoroborate $\left(\mathrm{NO}_{2} \mathrm{BF}_{4}\right)$, a chemical which requires aggressive reagents for its synthesis, is required for the preparation of these reactants, whilst more recent methods utilising either silver salts ${ }^{24}$ or Lewis acids (e.g. $\left.\mathrm{BF}_{3}\right)^{25}$ can be ruled out on grounds of hazard and expense. Hence currently available routes to nitrate esters are unsuitable for clean synthesis and alternatives need to be sought.

\section{Nitramines}

\section{RESULTS AND DISCUSSION}

In an attempt to overcome the twin problems of controlling the direction of nitrolysis reactions and forming more easily handlable co-products, the replacement of acyl functions by other readily nitrolysable groups was considered. It was felt that these problems stemmed largely from the inertness of the nitrogen atom towards electrophilic attack as a result of the electron-withdrawing acyl function, and therefore employment of substituents with the opposite inductive effect, i.e. electron-donating substituents, would be beneficial. With this rationale in mind, obvious candidate elements for consideration would be the group IV metalloids, and it was already known that stannylamines could be nitrolysed to yield nitramines ${ }^{26}$. Furthermore, publications in the mid-1980s had indicated that $\mathrm{C}$-silyl compounds could be cleaved by reagents such as nitronium tetrafluoroborate to yield $\mathrm{C}$-nitro compounds 27 . However, as no reports were known of the nitrolysis of the corresponding $\mathrm{N}$-silyl compounds, silylamines (VI), this therefore seemed an obvious class of compound to examine.

In the subsequent discussion, the $\mathrm{N}$-silyl substrates are divided into three categories - i) dialkylsilylamines, ii) cyclic disilylamines (including silylaziridines), and iii) silylamides, with seventeen examples in all. The nitrodesilylation reactions of twelve silyl ethers are described later.

\section{i) Dialkylsilylamines}

The silylamines (VI) were derived from the corresponding secondary amines, formed in situ where necessary (e.g. VIm). Reaction with dinitrogen pentoxide $\left(\mathrm{N}_{2} \mathrm{O}_{5}\right)$ in halogenated solvents such as dichloromethane generated the nitramines (I) cleanly and in good to excellent yield (Eqn. 2 and Table 1). The<smiles>[R]NN</smiles>

amine

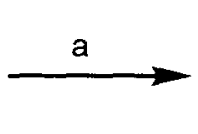<smiles>CC[Si](P)(CC)CP</smiles>

VI

silylamine<smiles>[R]N([R])[N+](=O)[O-]</smiles>

$\mathrm{O}_{2} \mathrm{NOSiR}_{3} \quad \mathrm{VII}$ silyl nitrate

(VIIa, $R=\mathrm{Me}$ )

[Reagents:- a) silylating agent $\left(\mathrm{R}^{\mathrm{n}}{ }_{3} \mathrm{SiX}\right.$ where $\mathrm{X}$ is a leaving group such as halogen, dialkylamino etc)

b) nitrating agent, esp. $\mathrm{N}_{2} \mathrm{O}_{5}$, also $\mathrm{NO}_{2} \mathrm{BF}_{4}$ ] 
reaction was found to be general for a range of alkyl substituents both on nitrogen ( $R$ \& $R^{\prime}$ ) and silicon (R"), with the highest yields being obtained with trimethylsilyl derivatives $\left(\mathrm{R}^{\prime \prime}=\mathrm{CH}_{3}\right.$, see Table 1). The reaction is applicable to cases which have proved troublesome in the past, for instance sterically hindered nitramines such as If, and yields were in many cases improved, sometimes markedly, upon those hitherto obtained.

\section{ii) Disilylamines and Silylaziridines}

Cyclic dinitramines (II \& Im) were likewise preparable without difficulty from the corresponding disilyl precursors. It is notable that the precursor to Im, N, $\mathrm{N}^{\prime}$-bis-(trimethylsilyl)hexahydropyrimidine (IIm, Table 1) is derived from an unstable diamine (hexahydropyrimidine, VIII) and highlights an intrinsic advantage of the novel nitration over other methods which require the use of the free amine, which may be unavailable. Furthermore, the dinitramine product (Im), which contains a geminal dinitramine moiety which is a substructural fragment found in the RDX and HMX molecules, is preparable in a yield (69\%) twice that<smiles>C1CNCNC1</smiles>

VIII<smiles>O=NN1CCCN(O)C1</smiles>

IX

reported in the hitherto best method (by nitro-denitrosation of the $\mathrm{N}, \mathrm{N}^{\prime}$-dinitroso compound $\mathbf{I X} \mathbf{X}^{28}$ ). This hints at the potential of this reaction, and its viability is subject only to the availability of suitable silylated precursors; in this respect, few limitations have been encountered, one of the few groups which is incompatible with silylating agents being the nitrile group.

The behaviour of one substrate, the $\mathrm{N}$-trimethylsilylaziridine $\mathbf{V} \mathbf{I k}^{29}$ was notable. Upon reaction with $1 \mathrm{~mol} \mathrm{~N}_{2} \mathrm{O}_{5}$ the $\mathrm{N}$-nitroaziridine $\mathrm{X}$ was formed in situ in ca $80 \%$ yield, and further reaction with excess of the reagent resulted in the formation of the N,N-dinitramine-nitrate $\mathbf{X I}$ (Eqn. 3), which was characterised

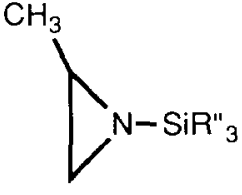

VIk

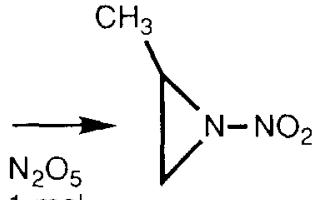

$\mathbf{X}$

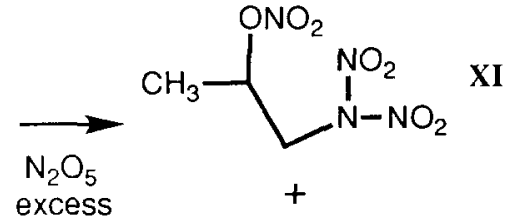

$\mathrm{O}_{2} \mathrm{NOCH}\left(\mathrm{CH}_{3}\right) \mathrm{CH}_{2} \mathrm{ONO}_{2}$

XII

spectroscopically, the nitramine asymmetric stretching band in the i.r. being observed at $1607 \mathrm{~cm}^{-1}$, in line with findings from other work ${ }^{30}$. The formation of the $\mathrm{N}$-nitroaziridine $\mathbf{X}$ constitutes the second reported synthesis of this class of compound 31 and the first by direct electrophilic substitution, although a Nnitroaziridine intermediate was postulated in earlier work on the nitration of propyleneimine by $\mathrm{N}_{2} \mathrm{O}_{5} 32$. Also, the N,N-dinitramine-nitrate XI was contaminated with some propane-1,2-diol dinitrate (XII); such compounds are known to be decomposition products of $\mathrm{N}, \mathrm{N}$-dinitramines ${ }^{33}$. Therefore the behaviour of this silylamine opens the door to some novel chemistry by affording classes of compounds which are only otherwise obtainable with extreme difficulty, and furthermore by the ring-opening nitration yields highenergy compounds such as $\mathbf{X I}$ which possesses a similar oxygen balance to nitroglycerine. 
Table 1: Reactions of Silylamines with $\mathrm{N}_{2} \mathrm{O}_{5}$

1. Monosilylamines $\quad \mathrm{R}^{1} \mathrm{R}^{2} \mathrm{~N}-\mathrm{Si}\left(\mathrm{R}^{3}\right)_{2} \mathrm{R}^{4} \quad \frac{\underline{\mathrm{Rn} .}}{(\mathrm{hr})} \quad \frac{\frac{\mathrm{Rn} .}{\mathrm{Temp}}}{\left({ }^{\circ} \mathrm{C}\right)} \quad \frac{\frac{\text { Yield of }}{\text { Nitramine }}}{\mathrm{R}^{1} \mathrm{R}^{2} \mathrm{~N}-\mathrm{NO}_{2}}$

\begin{tabular}{|c|c|c|c|c|c|c|c|}
\hline$\frac{\text { No. }}{\text { VI }}$ & $\mathbf{R}^{1}$ & $\mathrm{R}^{2}$ & $\mathrm{R}^{3}$ & $\mathrm{R}^{4}$ & & & $\begin{array}{c}(\%) \\
I\end{array}$ \\
\hline $\mathbf{a}$ & $-\left(\mathrm{CH}_{2}\right)_{2} \mathrm{O}(\mathrm{C}$ & $\left.\mathrm{CH}_{2}\right)_{2^{-}}$ & $\mathrm{CH}_{3}$ & $\mathrm{CH}_{3}$ & 2 & $0 \pm 2$ & 80 \\
\hline b & $-\left(\mathrm{CH}_{2}\right)_{5}$ & & $"$ & $"$ & 0.75 & $-5 \pm 2$ & 81 \\
\hline c & $-\left(\mathrm{CH}_{2}\right)_{4}$ & & $"$ & $"$ & 0.5 & -7 to -1 & 76 \\
\hline d & $\mathrm{CH}_{3}$ & $\mathrm{CH}_{3}$ & $"$ & $"$ & 0.75 & $-5 \pm 2$ & 78 \\
\hline e & $\mathrm{C}_{2} \mathrm{H}_{5}$ & $\mathrm{C}_{2} \mathrm{H}_{5}$ & $"$ & $"$ & 0.75 & $-5 \pm 2$ & 84 \\
\hline f & $\mathrm{i}-\mathrm{C}_{4} \mathrm{H}_{9}^{\dagger}$ & $\mathrm{i}-\mathrm{C}_{4} \mathrm{H}_{9}$ & $"$ & $"$ & 0.75 & -5 to 0 & 87 \\
\hline g & $-\left(\mathrm{CH}_{2}\right)_{2} \mathrm{O}$ & $\left(\mathrm{CH}_{2}\right)_{2-}^{-}$ & $"$ & $\mathrm{t}-\mathrm{C}_{4} \mathrm{H}_{9}$ & $\left\{\begin{array}{l}2.25 \\
6\end{array}\right.$ & $\begin{array}{c}0 \text { to }+5 \\
+5 \text { to }+10\end{array}$ & $\begin{array}{l}37 \\
40^{*}\end{array}$ \\
\hline h & $"$ & & $\mathrm{n}-\mathrm{C}_{4} \mathrm{H}_{9}$ & n- $\mathrm{C}_{4} \mathrm{H}_{9}$ & 1.5 & -5 to +5 & 39 \\
\hline i & $"$ & & $\mathrm{C}_{2} \mathrm{H}_{5}$ & $\mathrm{C}_{2} \mathrm{H}_{5}$ & 0.75 & 0 to +5 & $61 *$ \\
\hline $\mathrm{j}$ & $\mathrm{i}-\mathrm{C}_{4} \mathrm{H}_{9}{ }^{\dagger}$ & $\mathrm{i}-\mathrm{C}_{4} \mathrm{H}_{9}$ & $"$ & $"$ & 1 & 0 to +5 & 70 \\
\hline $\mathbf{k}$ & $-\mathrm{CH}_{2}-\mathrm{CI}$ & $\mathrm{H}\left(\mathrm{CH}_{3}\right)-$ & $\mathrm{CH}_{3}$ & $\mathrm{CH}_{3}$ & $10 \mathrm{~min}$ & $0 \pm 5$ & $\ddagger$ \\
\hline
\end{tabular}

2. Disilylamines

1<smiles>C[SiH]N1CCN([SiH3])CC1</smiles>

-8 to 0

91

m

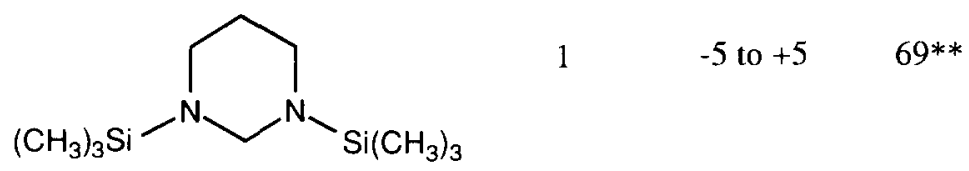

\footnotetext{
Notes * Larger excesses of $\mathrm{N}_{2} \mathrm{O}_{5}$ (50 and 100\% resp.) used

** Mode of addition reversed $\left(\mathrm{N}_{2} \mathrm{O}_{5}\right.$ added to silylamine)

${ }_{\mathrm{i}} \mathrm{-}-\mathrm{C}_{4} \mathrm{H}_{9}=\left(\mathrm{CH}_{3}\right)_{2} \mathrm{CHCH}_{2}$ -

$\ddagger$ N-Nitroaziridine not isolated - reacted further in situ (see text)
} 
Table 2: Reactions of Silylamides with $\mathrm{N}_{2} \mathrm{O}_{5}$

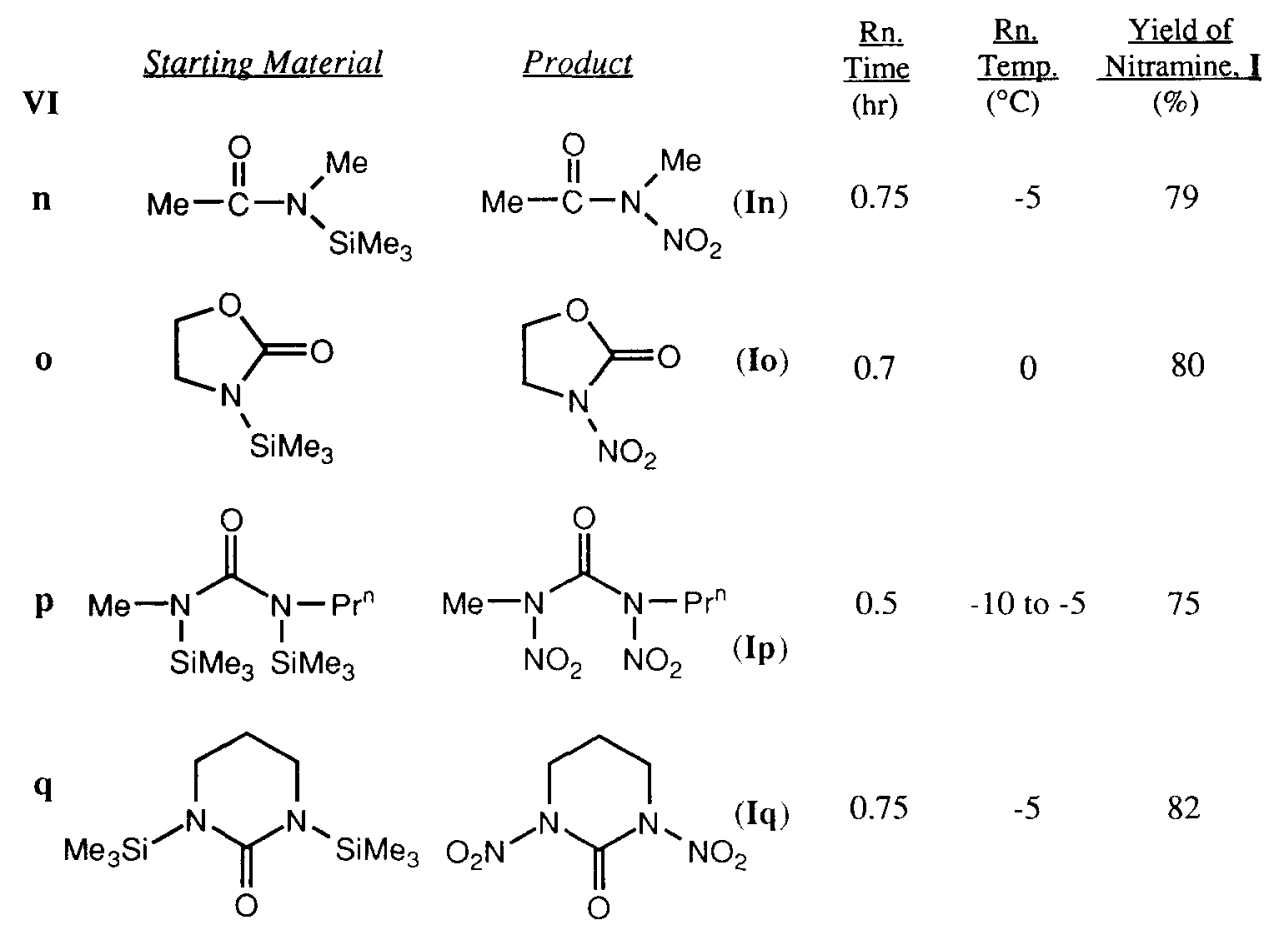

iii) Silylamides

Three representative classes of acyl substrates were investigated: one amide (VIn), one carbamate (VIo) and two ureas - VIp (acyclic) and VIq (cyclic); see Table 2. All gave the corresponding nitramine derivatives in good yields (75-82\%), which in two cases (VIn \& VIo) were significant improvements upon those obtained previously (27\% and $53 \%$ respectively 34 ). The acyclic dinitrourea (Ip) was a new compound, prepared from the known silyl precursor VI $\mathbf{I p}^{35}$, while preparation of the cyclic dinitrourea (Iq), although feasible by direct nitration of trimethyleneurea (XIII) in $87 \%$ yield 36 was nevertheless facilitated by the nitrodesilylation route by the aforementioned advantages of simplified workup and absence of contaminating by-products.

\section{Nitrate Esters}

It was considered that O-silyl compounds, i.e. trialkylsilyl ethers (XIII), might behave analogously to $\mathrm{N}$-silyl compounds and yield nitrate ester products (XIV), gaining similar advantages to those realised in the nitramine syntheses (Eqn. 4).

\section{i) Acyclic silyl ethers}

These silyl ethers, which share the common feature that the silicon atom bears only one O-substituent, were prepared from the corresponding alcohols by literature methods ${ }^{37}$. In the case of trimethylsilyl ethers, hexamethyldisilazane was used (Eqn. 5) and this was applied to both monohydric (XIIIa-c, g) as well as 


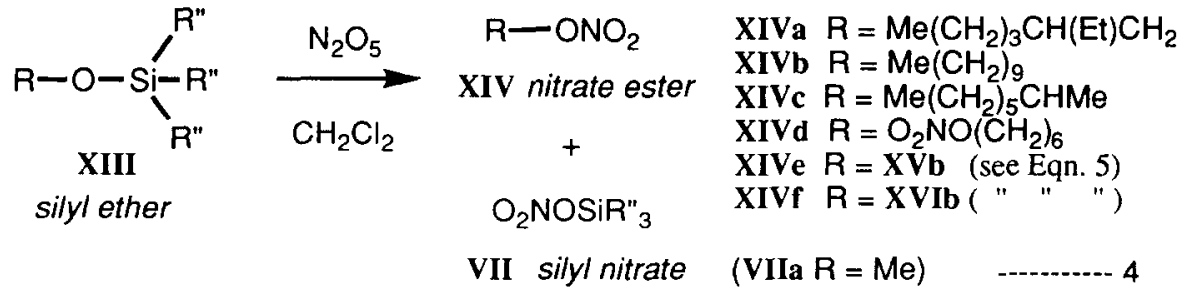

dihydric (XIIId - f) examples. Derivatives with longer alkyl chains were prepared from the corresponding silyl chlorides in the presence of an auxiliary base and a catalyst (4-(dimethylamino)pyridine, DMAP; Eqn. 6). Preparative yields were generally in the range 75 to $93 \%$. In one case (XIIIg) a second functionality (an aziridine ring) was present in the molecule, offering the possibility of introducing further energetic moieties by ring-opening nitration ${ }^{38}$.

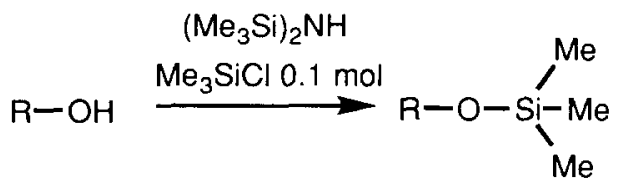<smiles>CCC1(C)CCCCC1</smiles>

$\mathrm{XVaR}=\mathrm{Me}_{3} \mathrm{SiO}$ $\mathrm{XVb} \mathrm{R}=\mathrm{O}_{2} \mathrm{NO}$<smiles>[R]CC1(CC)COC1</smiles>

XVIa $\mathrm{R}=\mathrm{Me}_{3} \mathrm{SiO}$ XVIb $\mathrm{R}=\mathrm{O}_{2} \mathrm{NO}$
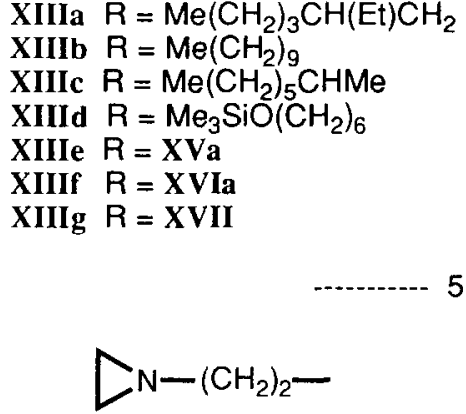

XVII

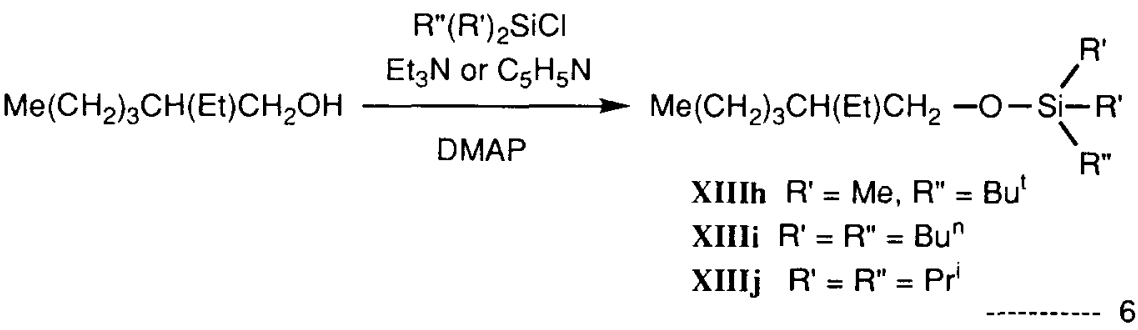

When the simple trimethylsilyl ethers XIIIa-d were treated with a small excess of $\mathrm{N}_{2} \mathrm{O}_{5}$ in dichloromethane, the corresponding nitrate esters XIVa-d were obtained cleanly and in high (83-92\%) yield (see Eqn 4 and Table 3, entries i) - iv)). The secondary example (XIIIc) reacted more slowly but the ultimate yield of nitrate ester XIVc (after $5 \mathrm{~h}$ at ambient temperature) was in line with the other examples. The difunctional trimethylsilyl ethers XIIIe-f gave much lower yields owing to the neopentyl situation of the silyl ether functions, which gives rise to much reduced reactivity because of steric hindrance. The remaining trimethylsilyl ether, XIIIg, was treated with $2 \mathrm{~mol} \mathrm{~N}_{2} \mathrm{O}_{5}$ to enable reaction to occur on the aziridine function as well as the silyl ether, and a moderate (56\%) yield of the known nitramine-nitrate (DINA, XVIII) was obtained (Eqn. 7) 


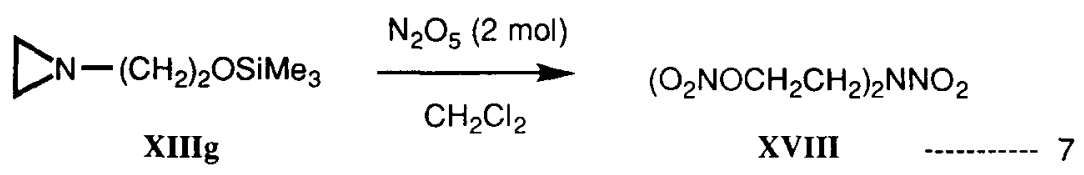

The remaining acyclic silyl ethers XIIIh-j (Table 3, entries viii) - $x$ )), which bore longer alkyl chains (up to $\mathrm{C}_{4}$ ) on the silicon atom (the alcohol chain, $\mathrm{R}$, was in all cases 2-ethylhexyl), in general reacted more slowly with $\mathrm{N}_{2} \mathrm{O}_{5}$, mirroring the trends found in the silylamine reactions (see above). In particular, those with branched alkyl substituents were the least reactive, and with tert.-butyldimethyl substitution on silicon a maximum yield of XIVa of only 35\% was attained, even under forcing conditions ( 100 molar \% excess of

Table 3: Reactions of Silyl Ethers with $\mathrm{N}_{2} \mathrm{O}_{5}$

\begin{tabular}{|c|c|c|c|c|c|c|}
\hline Entry & Silyl Ether & 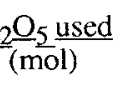 & $\frac{\mathrm{Rn} . \text { Temp. }}{{ }^{\circ} \mathrm{C}}$ & $\frac{\mathrm{Rn} \text {. Time }}{\mathrm{h}}$ & $\frac{\text { Nitrate }}{\underline{\text { Ester }}}$ & $\frac{\text { Yield }}{\%}$ \\
\hline i) & 2-ethylhexanol TMS (XIIIa) & 1.1 & -5 to +8 & 1.5 & XIVa & 92 \\
\hline ii) & n-decanol TMS (XIIIb) & 1.1 & -5 to +8 & 1.5 & XIVb & $87^{*}$ \\
\hline iii) & 2-octanol TMS (XIIIc) & 1.1 & -5 to +15 & $5^{\dagger}$ & XIVe & 88 \\
\hline iv) & hexane-1,6-diol bis-TMS (XIIId) & 2.2 & -5 to +3 & 0.75 & XIVd & 83 \\
\hline v) & $\begin{array}{l}\text { 2,2-(pentamethylene)-propane- } \\
\text { 1,3-diol bis-TMS (XIIIe) }\end{array}$ & $5.5 * *$ & -20 to +10 & 1.5 & XIVe & $* *$ \\
\hline vi) & 3,3-bis(TMSoxymethyl)oxetane (XIIIf) & If) 2.2 & -5 & 2.0 & XIVf & 35 \\
\hline vii) & 2-aziridineethanol TMS (XIIIg) & 2.2 & -10 to +5 & 1.5 & XVIII & $56^{\dagger \dagger}$ \\
\hline viii) & 2-ethylhexanol TBDMS (XIIIh) & 1.15 & -5 to +5 & 18 & XIVa & $<5$ \\
\hline viii)a & $"$ & 2.0 & -5 & 18 & " & 35 \\
\hline ix) & 2-ethylhexanol tri(n-butyl) (XIIIi) & 1.1 & -5 & 18 & XIVa & 87 \\
\hline ix)a & $"$ & 2.0 & -5 & 18 & " & 94 \\
\hline $\mathrm{x})$ & 2-ethylhexanol tri(isopropyl)(XIIIj) & 1.1 & -5 & 18 & XIVa & 29 \\
\hline $\mathrm{x}) \mathrm{a}$ & $"$ & 2.0 & -5 & 18 & $"$ & 53 \\
\hline xi) & $\begin{array}{l}\text { 2,2-dimethylpropane-1,3-diol } \\
\text { cyclic DMS (XIX) }\end{array}$ & 2.2 & -10 to +3 & 1.5 & XXII & $\ddagger$ \\
\hline xii) & butane-1,2-diol cyclic DMS ( $\mathbf{X X})$ & 5.0 & -5 & 24 & XXIII & 66 \\
\hline$\underline{\text { Notes }}$ & $\begin{array}{ll}* & \text { The organic extract floated on brine. } \\
\dagger & \text { Reaction was incomplete after } 2.5 \mathrm{~h}(\mathrm{nmr}) \\
* * & \text { Impure product obtained, also with lower } \\
\dagger \dagger & \text { Nitramine-nitrate prepared, but impure. } \\
\ddagger & \text { Main product obtained is silyl nitrate (for }\end{array}$ & r) mol ratios & $\begin{array}{l}\text { of } \mathrm{N}_{2} \mathrm{O}_{5} \text {. } \\
\sec (\mathrm{text})\end{array}$ & & & \\
\hline
\end{tabular}


$\mathrm{N}_{2} \mathrm{O}_{5}$ for $18 \mathrm{~h}$ ). These findings indicate that if, for instance, it were necessary to use a tert.-butyldimethylsilyl ether in a synthetic strategy (e.g. as a blocking group) then the nitrate ester could not be generated efficiently by direct reaction with $\mathrm{N}_{2} \mathrm{O}_{5}$, and alternative strategies might have to be sought. Completing the reactivity comparison of compounds XIIIh-j, it is apparent that the tri(n-butyl) derivative is the most reactive towards $\mathrm{N}_{2} \mathrm{O}_{5}$, giving similar yields to the trimethylsilyl examples (although with substantially longer reaction times), whilst the tri-(isopropyl) derivative displays an intermediate reactivity, yielding up to $53 \%$ nitrate ester XIVa.

\section{ii) Cyclic silyl ethers}

Two compounds in this class were studied: XIX and XX. They were prepared (Eqn. 8) from the corresponding 1,2- or 1,3-diols by reaction with dichlorodimethylsilane according to the literature ${ }^{39}$. The products obtained upon treatment with $\mathrm{N}_{2} \mathrm{O}_{5}$ were strongly dependent on the conditions. Thus with XIX, use of a small excess of $\mathrm{N}_{2} \mathrm{O}_{5}$ and a short reaction time resulted in the isolation of very little of the desired dinitrate XXI, and the major product was the partially cleaved silyl nitrate XXII. This compound belongs to a

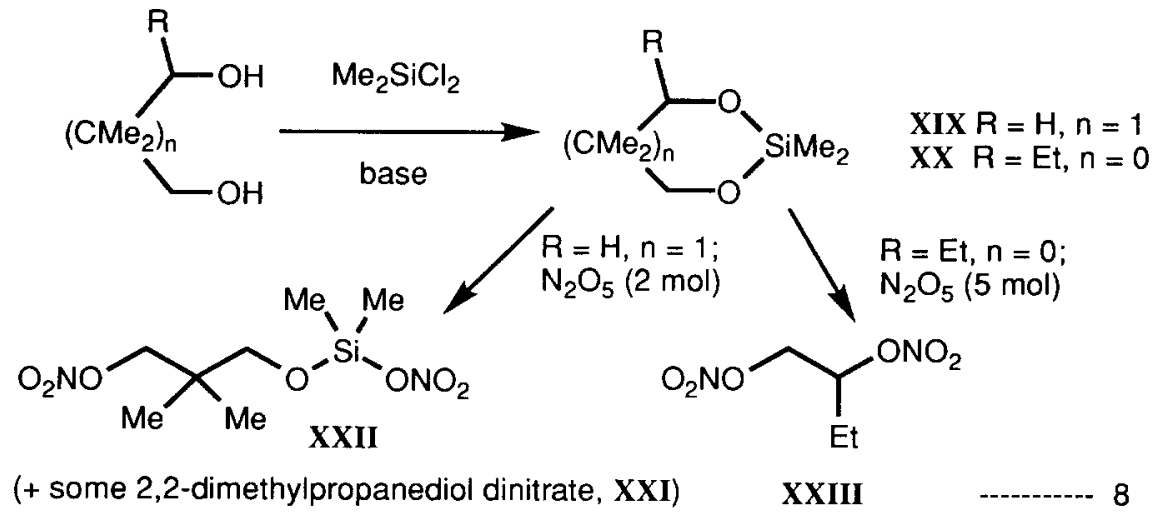

class of compounds, the silyl nitrates, which have received scant attention in the literature 40 . It showed interesting spectral properties whereby unusual nitrate ester bands at 1263 (symm. $\mathrm{NO}_{2}$ stretch) and 808 $\left(\mathrm{ONO}_{2}\right.$ group) $\mathrm{cm}^{-1}$ were observed, which were at lower frequencies than those of $\mathrm{C}$-nitrates by some 15 and $60 \mathrm{~cm}^{-1}$ respectively, presumably on account of the attachment of the heavier silicon atom in place of carbon.

On the other hand, when silyl ether $\mathbf{X X}$ was treated with a large (150\%) excess of $\mathrm{N}_{2} \mathrm{O}_{5}$ and allowed to react for a protracted period, the dinitrate XXIII was obtained in useful (66\%) yield (Eqn. 8). Presumably XIX would also give a substantial yield of XXI under similar conditions, but insufficient sample remained to test this hypothesis.

\section{Conclusions}

Therefore nitrodesilylations of silylamines and silyl ethers by $\mathrm{N}_{2} \mathrm{O}_{5}$ afford the corresponding nitro compounds, nitramines and nitrate esters respectively, generally in good to excellent yields. With the silylamines the reaction ${ }^{41}$ is of wide applicability, and products bearing 1,3-bis-(N-nitro) functions are accessible such as Im. This result augurs well for the extension of the method to polynitramines such as RDX. The conditions necessary to effect the cleavage of the N-Si bond are much milder than, for instance, those required to cleave $\mathrm{N}$-acyl substrates (i.e. amides) and suggest applications in those areas where cleavage of acetamides has failed to yield nitramine products, e.g. polycyclic nitramines such as bicyclo-HMX ${ }^{21}$. 
Likewise the reaction of silyl ethers with $\mathrm{N}_{2} \mathrm{O}_{5}$ is a viable means of synthesising nitrate esters, particularly when the alkyl silicon substituents possess short or unbranched chains (particularly methyl), and yields in excess of $90 \%$ can be realised. However, when these substituents are branched chains the yields are lower, and with tert.-butyl derivatives the yield is only acceptable under forcing conditions. Therefore the use of short chain derivatives is preferable. Also the silyl ethers differ from the silylamines, where reactivities were in general higher, even on electron-deficient functions such as amides. The reactivity trends are in line with the difference in basicity of these elements resulting from the relative availability of the electrons in their respective lone pairs to participate in bonding. Thus the nitrogen lone pair is loosely bound and hence can readily form a sigma bond on approach of an electrophile such as the nitronium ion (which exists in $\mathrm{N}_{2} \mathrm{O}_{5}$ solutions under laboratory conditions ${ }^{42}$ ). On the other hand, the more tightly bound lone pairs on oxygen are more reluctant to do so, resulting in lower reactivities with this class of compound, in agreement with experimental observation.

The by-product from the nitration reaction, the volatile silyl nitrate $\left(\mathrm{CH}_{3}\right)_{3} \mathrm{SiONO}_{2}\left(\mathrm{VII}, \mathrm{R} "=\mathrm{CH}_{3}\right.$, Eqns. $2 \& 4$ ), is a nitrating agent in its own right - for instance it can convert toluene to dinitrotoluene 43 , and it showed potential for recycling (see Experimental, "Reactions of Silyl Ethers"). The formation of silyl nitrates such as VII is also preferable to the acidic by-products (viz. $\mathrm{BF}_{3}$ or $\mathrm{HBF}_{4}$ ) which would arise from the corresponding reactions with $\mathrm{NO}_{2} \mathrm{BF}_{4}$. Furthermore the non-acidic reaction medium is suitable for applications involving acid-sensitive substrates hitherto precluded from study in conventional nitration media.

Finally, it should be emphasised that this approach to nitramines and nitrate esters comprises a novel alternative to methods employing strong mineral acids, and, once fully developed, will overcome many of the problems inherent in the latter concerning the disposal of waste acid liquors. Nitrodesilylation methodologies such as those described here are well placed to meet new environmental legislation ${ }^{44}$, and offer the opportunity to solve many of the problems inherent in the clean manufacture of energetic ingredients for munitions applications.

\section{Acknowledgements}

This work was undertaken with the support of the Ministry of Defence (Strategic Research, "New Synthetic Routes Phase 2"). Thanks are also due to Mr N. C. Paul and Dr R. P. Claridge for helpful discussions.

\section{EXPERIMENTAL}

\section{Materials and apparatus}

Silylamines VIa, VIc, VId \& VIe were purchased from Aldrich Chemical Co, and silylamides VIn and VIo from Fluka Chemicals. The remaining silylamines were prepared as follows:- $n$-alkylsilylamines derived from strong bases by direct reaction with chlorotrimethylsilane in the presence of a proton acceptor (triethylamine), either as described in the literature: $\mathbf{V I b}^{45}, \mathbf{V I I}{ }^{46}$, or by modified literature methods: VIh and VIi. Trimethylsilylamines derived from weaker bases, or silylamines bearing branched alkyl substituents on Si were prepared by lithiating the amine using n-butyllithium prior to reaction with the chlorosilane 47,48 : VIf, VIg and VIj. The $\mathrm{N}$-silylaziridine VIk was prepared by the reaction of propyleneimine with chlorotrimethylsilane in n-pentane ${ }^{29}$. Physical data of these materials are as follows: VIf: b.pt. $72^{\circ} \mathrm{C} / 10 \mathrm{~mm} ;{ }^{1} \mathrm{H} \mathrm{nmr}, \delta$ : $-0.05(\mathrm{~s}, 9) ; 0.75(\mathrm{~d}, 12) ; 1.70(\mathrm{sp}, 2) ; 2.45(\mathrm{~d}, 4) \mathrm{ppm}$; i.r. $v_{\max }$ (liquid film): $1468(\mathrm{~m}), 1386(\mathrm{~m}), 1367(\mathrm{~m})$, 
1318 (w), 1260 (m), 1248 (s) cm-1; VIg: b.pt. $120-130^{\circ} \mathrm{C} / 15 \mathrm{~mm} ;{ }^{1} \mathrm{H} \mathrm{nmr}, \delta: 0.05$ (s,6); 0.90 (s,9); 2.91 (t,4), $3.55(\mathrm{t}, 4)$; i.r. $v_{\max }$ (liquid film): $1471(\mathrm{w}), 1386(\mathrm{~m}), 1372(\mathrm{~m}), 1258(\mathrm{~s}), 1159(\mathrm{~m}), 1258$ (s) cm-1; VIh: b.pt. $160-163^{\circ} \mathrm{C} / 9 \mathrm{~mm} ;{ }^{1} \mathrm{H} \mathrm{nmr}, \delta: 1.1(\mathrm{~m}, 29) ; 2.83(\mathrm{t}, 4) ; 3.55(\mathrm{t}, 4) \mathrm{ppm}$; i.r. $v_{\max }$ (liquid film): 1457 (w), 1374 (m), $1255(\mathrm{~m}), 1160(\mathrm{w}), 1116(\mathrm{~s}), 1080(\mathrm{~m}) \mathrm{cm}^{-1}$; VIi: b.pt. $155-160^{\circ} \mathrm{C} / 47 \mathrm{~mm} ;{ }^{1} \mathrm{H} \mathrm{nmr}, \delta: 0.6(\mathrm{~m}, 15) ; 2.80$ $(\mathrm{t}, 4) ; 3.50(\mathrm{t}, 4)$; i.r. $v_{\max }$ (liquid film): $1456(\mathrm{w}), 1371(\mathrm{w}), 1256(\mathrm{~m}), 1161(\mathrm{~m}), 1115$ (s) cm-1; VIj: b.pt. $125-$ $130^{\circ} \mathrm{C} / 1.5 \mathrm{~mm} ;{ }^{1} \mathrm{H} \mathrm{nmr}, \delta: 0.8(\mathrm{~m}, 27) ; 1.72(\mathrm{sp}, 2) ; 2.45$ (d,4); i.r. $v_{\max }$ (liquid film): $1466(\mathrm{~m}), 1385(\mathrm{~m})$, $1366(\mathrm{w}), 1163(\mathrm{~m}), 1029(\mathrm{~s}) \mathrm{cm}^{-1}$.

The remaining silylamine (VIm) was prepared by the following novel procedure: hexahydropyrimidine $(3.0 \mathrm{~g})$ in anhydrous ether solution $(150 \mathrm{ml})$, prepared as described in the literature ${ }^{49}$, to which triethylamine $(7.05 \mathrm{~g})$ had been added, was treated with chlorotrimethylsilane $(7.6 \mathrm{~g})$ at 15 to $20^{\circ} \mathrm{C}$ - further anhyd. ether was added to facilitate stirring. After $20 \mathrm{~min}$. at this temperature, the mixture was filtered and concentrated (Rotavapor) to give a cloudy oil which was distilled (GKR) to give a mobile oil $(1.9 \mathrm{~g}), \mathrm{b} . \mathrm{pt} .90-5^{\circ} \mathrm{C} / 3$ $\mathrm{mm}$ ). A second batch distilled on the Spaltrohr had b.pt. $80-2^{\circ} \mathrm{C} / 6.5 \mathrm{~mm} ;{ }^{1} \mathrm{H} \mathrm{nmr}, \delta: 0.05(\mathrm{~s}, 18) ; 1.31(\mathrm{~m}, 2)$; $2.97(\mathrm{t}, 4) ; 3.92(\mathrm{~s}, 2) \mathrm{ppm}$; i.r. $v_{\max }$ (liquid film): $1452(\mathrm{~m}), 1385(\mathrm{~m}), 1365(\mathrm{~m}), 1250(\mathrm{~s}), 1200(\mathrm{~m}) \mathrm{cm}^{-1}$.

Silylamide VIp was prepared by modified literature procedure from $n$-propyl isocyanate and heptamethyldisilazane ${ }^{35}$; VIq was prepared by silylation of the trimethyleneurea using $\mathrm{N}$-trimethylsilyltrifluoroacetamide as follows:- N,N'-Trimethyleneurea (3,4,5,6-tetrahydro-2 $(1 H)$-pyrimidinone) $(5.80 \mathrm{~g}, 50$ $\mathrm{mmol}$ ) and $\mathrm{N}$-methyl- $\mathrm{N}$-(trimethylsilyl)trifluoroacetamide $(24.9 \mathrm{~g}, 125 \mathrm{mmol})$ in acetonitrile $(30 \mathrm{ml}$, dried over 4A molecular sieve) were heated under reflux for $18 \mathrm{hr}$ under an atmosphere of dry nitrogen. The mixture was cooled and, after removal of the solvent under reduced pressure, bulb-to-bulb distillation of the residue gave a fore-run of $\mathrm{N}$-methyltrifluoroacetamide, b.pt. $<100^{\circ} \mathrm{C} / 1.0 \mathrm{~mm}$, followed by the main fraction, b.pt. $110-120^{\circ} \mathrm{C} / 0.8 \mathrm{~mm}, 3.0 \mathrm{~g}(22 \%)$, identified as $\mathrm{N}, \mathrm{N}^{\prime}$-bis(trimethylsilyl)-N, $\mathrm{N}^{\prime}$-trimethyleneurea from its ${ }^{1} \mathrm{H} \mathrm{nmr}$ spectrum and m.pt of $78-79^{\circ} \mathrm{C}$ (lit. $\left.{ }^{50} \mathrm{~m} . \mathrm{pt} .78-80^{\circ} \mathrm{C}\right) ;{ }^{1} \mathrm{H} \mathrm{nmr}, \delta: 0.20(\mathrm{~s}, 18) ; 1.70(\mathrm{~m}, 2) ; 3.15(\mathrm{t}, 4)$ ppm; i.r. $v_{\max }$ (liquid film): 1692, 1666, 1438, 1306, 1249, $845 \mathrm{~cm}^{-1}$.

The following trimethylsilyl ethers were prepared 37 by treatment of the corresponding alcohol with hexamethyldisilazane [HMDS] with a trace of chlorotrimethylsilane [CTMS] as follows:-

2-Ethylhexanol, n-decanol and 2-octanol: A mixture of the alcohol (0.2 mol) and HMDS (0.11 mol), to which a few drops of CTMS had been added, was heated with stirring in an oil bath in a RB flask equipped with an air condenser, initially at 60 to $65^{\circ} \mathrm{C}$. The temperature was raised progressively to $150^{\circ} \mathrm{C}$ over $2-3 \mathrm{~h}$ (evolution of ammonia noted - moist indicator paper check) and the reaction was held at this temperature overnight, or until no further ammonia could be detected. The product was then distilled, either bulb-to-bulb on a Büchi Kugelrohr GKR 50 (\#) or by fractionation (Fisher Spaltrohr HMS 300 (\$) or $10 \mathrm{~cm}$ Vigreux column ( $(\mathbb{)})$ ), to give the pure silyl ether. Thus prepared were:- i) 2-ethylhexanol trimethylsilyl ether (XIIIa), b.pt.(ף) $88-89^{\circ} \mathrm{C} / 20 \mathrm{~mm}(85 \%) ;{ }^{1} \mathrm{H} \mathrm{nmr}, \delta: 0.20(\mathrm{~s}, 9) ; 1.00(\mathrm{t}, 6) ; 1.35(\mathrm{~m}, 8) ; 3.5(\mathrm{~m}, 2) ; v_{\max }$ (liq. film): $2959(\mathrm{~s})$, 2930(s), 2867(s), 1462(m), 1382(m), 1251(s), 1092(s), 878(s), 841(s), 746(m) cm-1; ii) n-decanol trimethylsilyl ether (XIIIb), b.pt. (\#) $164^{\circ} \mathrm{C} / 90 \mathrm{~mm}(75 \%) ;{ }^{1} \mathrm{H} \mathrm{nmr}, \delta: 0.20(\mathrm{~s}, 9) ; 0.95(\mathrm{t}, 3) ; 1.32$ (brs, 16); 3.60(t,2); $v_{\max }$ (liq. film): 2956(s), 2926(s), 2855(s), 1467(m), 1384(m), 1250(s), 1100(s), 841(s), 746(m) cm-1; iii) 2octanol trimethylsilyl ether (XIIIc), b.pt. (I) $95-99^{\circ} \mathrm{C} / 30 \mathrm{~mm}(74 \%) ;{ }^{1} \mathrm{H} \mathrm{nmr}, \delta: 0.15(\mathrm{~s}, 9) ; 0.85(\mathrm{~m}, 3)$; $1.00(\mathrm{~d}, 3) ; 1.2(\mathrm{~m}, 10) ; 3.65(\mathrm{~m}, 1) ; \mathrm{lit}^{51}: \delta\left(\mathrm{CDCl}_{3}\right) 0.10(\mathrm{~s}, 9) ; 0.88(\mathrm{t}, 3) ; 1.13(\mathrm{~d}, 3) ; 1.18-1.50(\mathrm{~m}, 10) ; 3.75(\mathrm{~m}, 1) ;$ $v_{\max }$ (liq. film): 2958(s), 2928(s), 2859(s), 1459(m), 1374(m), 1250(s), 1084(m), 841(s), 747(m) $\mathrm{cm}^{-1}$. Hexane-1,6-diol, 2,2-(pentamethylene)propane-1,3-diol ${ }^{52}$ and 3,3-bis(hydroxymethyl)oxetane ${ }^{53}$ were treated 
as above, but using $0.10 \mathrm{~mol}$ diol and $0.11 \mathrm{~mol} \mathrm{HMDS} \mathrm{(with} \mathrm{CTMS).} \mathrm{Thus} \mathrm{prepared} \mathrm{were} \mathrm{iv)} \mathrm{hexane-1,6-diol}$ bis(trimethylsilyl) ether (XIIId), b.pt. (\#) $165-170^{\circ} \mathrm{C} / 15 \mathrm{~mm}(93 \%) ;{ }^{1} \mathrm{H} \mathrm{nmr}, \delta: 0.15(\mathrm{~s}, 18) ; 1.45(\mathrm{~m}, 8)$; 3.60(t,4); $v_{\max }$ (liq. film): 2938(s), 2861(s), 1385(m), 1251(s), 1096(s), 1036(m), 873(s), 841(s), 747(m) cm-1; v) 2,2-(pentamethylene)propane-1,3-diol bis(trimethylsilyl) ether (XIIIe), b.pt. (\$) $103.5-104^{\circ} \mathrm{C} / 4.5 \mathrm{~mm}$ (85\%); purity (by ${ }^{1} \mathrm{H} \mathrm{nmr}$ ) ca $90 \% ;{ }^{1} \mathrm{H} \mathrm{nmr}, \delta: 0.0(\mathrm{~s}, 18) ; 1.3$ (brs, 10$) ; 3.30(\mathrm{~s}, 4) ; v_{\max }$ (liq. film): $2955(\mathrm{~s})$, 2930(s), 2859(s), 1460(m), 1250(s),1086(s), 885(s), 841(s), 747(m) $\mathrm{cm}^{-1}$; and vi) 3,3-bis(trimethylsilyloxymethyl)oxetane (XIIIf), b.pt. (\#) $135-150^{\circ} \mathrm{C} / 10 \mathrm{~mm}(60 \%) ;{ }^{1} \mathrm{H} \mathrm{nmr}, \delta: 0.30(\mathrm{~s}, 18) ; 3.85(\mathrm{~s}, 4) ; 4.50(\mathrm{~s}, 4) ; v_{\max }$ (liq. film): 1252(s), 1085(s), 870(s), $841(\mathrm{~s}) \mathrm{cm}^{-1}$.

Long-chain silyl ethers 37 : 2-ethylhexanol tert.-butyldimethylsilyl ether (XIIIh), b.pt. (\#) $120^{\circ} \mathrm{C} / 8 \mathrm{~mm}$ (89\%); ${ }^{1} \mathrm{H} \mathrm{nmr}, \delta:-0.05(\mathrm{~s}, 6) ; 0.75$ (brs,5); 0.80(s,9); 1.2(brs, 10); 3.40(brs,2); $v_{\max }$ (liq. film): 2958(s), 2929(s), 2858(s), 1472(m), 1463(m), 1384(m), 1255(s), 1095(s), 850(s), 836(s), 774(s) $\mathrm{cm}^{-1} ;$ 2-ethylhexanol tri-(n-butyl)silyl ether (XIIIi): b.pt. (\#) $160-180^{\circ} \mathrm{C} / 0.5 \mathrm{~mm} ;{ }^{1} \mathrm{H} \mathrm{nmr}, \delta: 0.5-1.6\left(\mathrm{~m}, 42\right.$ ); 3.5 (br.s,2); $v_{\max }$ (liq. film): $1092 \mathrm{~cm}^{-1}$; 2-ethylhexanol tri-(isopropyl)silyl ether (XIIIj): b.pt. (\#) $160-180^{\circ} \mathrm{C} / 0.5 \mathrm{~mm} ;{ }^{1} \mathrm{H} \mathrm{nmr}, \delta$ : $1.0-1.7(\mathrm{~m}, 36) ; 3.5$ (br.s,2).

$\mathrm{N}_{2} \mathrm{O}_{5}$ was prepared by ozonation of $\mathrm{N}_{2} \mathrm{O}_{4}$ as described previously 54 and stored at $-70^{\circ} \mathrm{C}$ before use. Dichloromethane was dried by passage through a column of chromatographic silica gel (BDH) before use.

${ }^{1} \mathrm{H} \mathrm{nmr}$ spectra were recorded on a Varian Associates EM 360A nmr spectrometer equipped with an EM3630 homonuclear lock-decoupler operating at $60 \mathrm{MHz}$. Chemical shifts are reported in ppm downfield from TMS used as an internal standard, and the solvent used was $\mathrm{CDCl}_{3}$ unless otherwise indicated. Infra-red spectral measurements were carried out using a Nicolet 5SX FTIR spectrometer equipped with a DTGS detector. Melting points were determined in open capillaries on a Büchi 510 apparatus and are uncorrected.

CAUTION: All reactions utilising $\mathrm{N}_{2} \mathrm{O}_{5}$ were carried out in armoured cupboards.

\section{$\underline{2 . N_{2}} \underline{O}_{5} \underline{\text { Nitrations }}$}

\section{General method: Silylamines VIa-j and VII \& $\mathbf{m}$}

The silylamine (20 mmol) was dissolved in dichloromethane (10-15 ml) and added dropwise with stirring and cooling (at $-5 \pm 2^{\circ} \mathrm{C}$ ) to a solution of $\mathrm{N}_{2} \mathrm{O}_{5}(22 \mathrm{mmol})$ in the same solvent $(20-40 \mathrm{ml})$ [disilylamines VII and VIm were reacted with $44 \mathrm{mmol} \mathrm{N}_{2} \mathrm{O}_{5}$ ]. After addition was complete the mixture was stirred for the period shown at the temperature shown in Table 1 . The reaction mixture was then drowned in saturated $\mathrm{NaHCO}_{3}$ solution $(30-40 \mathrm{ml}$ ) and the organic layer separated. The aqueous layer was extracted with dichloromethane and the combined extracts were washed further with saturated sodium bicarbonate solution, dried over anhydrous $\mathrm{MgSO}_{4}$ and evaporated under water-pump vacuum below $30^{\circ} \mathrm{C}$. The nitramine products, Ia-m, were collected and characterised by m.pt., i.r. and nmr spectra; the majority were isolated as colourless solids (after trituration (ethanol) if necessary), except for Ib and Ie which were oils. In the case of Ia, the m.pt. of the product ( $\mathrm{N}$-nitromorpholine) was not depressed on admixture with an authentic sample, prepared from morpholine and $\mathrm{N}_{2} \mathrm{O}_{5}$ by the method of Emmons et al ${ }^{12}$. In certain cases (VIg, VIi and VIm), larger excesses of $\mathrm{N}_{2} \mathrm{O}_{5}(100,50$ and $100 \%$ resp.) were used, and owing to the instability of nitramine Im to acid, the mode of addition of the reagents was reversed, otherwise a highly impure product was obtained.

Thus prepared were the following: $\mathrm{N}$-nitromorpholine (la), m.pt. $50-51^{\circ} \mathrm{C}\left(\right.$ lit. $\left.{ }^{12} 50-52^{\circ} \mathrm{C}\right) ;{ }^{1} \mathrm{H} \mathrm{nmr}, \delta$ :

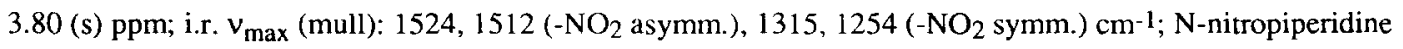


(Ib), oil, ${ }^{1} \mathrm{H} \mathrm{nmr}, \delta$ : 1.65 (m,6), 3.85 (m,4) ppm; i.r. $v_{\max }$ (liq. film): $1514\left(-\mathrm{NO}_{2}\right.$ asymm.), 1329, 1279, 1242 $\left(-\mathrm{NO}_{2}\right.$ symm.) $\mathrm{cm}^{-1} ; \mathrm{N}$-nitropyrrolidine (Ic), m.pt. $55.5-56.5^{\circ} \mathrm{C}$ (lit. $55,1256^{\circ} \mathrm{C}, 58-59^{\circ} \mathrm{C}$ resp.); ${ }^{1} \mathrm{H} \mathrm{nmr}, \delta$ : $2.00(\mathrm{~m}, 4), 3.70(\mathrm{~m}, 4)$ ppm; i.r. $v_{\max }$ (mull): $1500\left(-\mathrm{NO}_{2}\right.$ asymm.), 1307, $1280\left(-\mathrm{NO}_{2}\right.$ symm.) cm-1; dimethylnitramine (Id), m.pt. $54.5-55^{\circ} \mathrm{C}$ (lit. ${ }^{56} 58^{\circ} \mathrm{C}$ ); ${ }^{1} \mathrm{H} \mathrm{nmr}, \delta: 3.43(\mathrm{~m}) \mathrm{ppm}$; i.r. $v_{\max }$ (mull): 1500,1450 (-NO 2 asymm.), 1333, 1290, $1260\left(-\mathrm{NO}_{2}\right.$ symm.) cm-1; diethylnitramine (le), oil, ${ }^{1} \mathrm{H} \mathrm{nmr}, \delta: 1.25(\mathrm{t}, 6), 3.80$ $(\mathrm{qr}, 4) \mathrm{ppm}$; i.r. $v_{\max }$ (liq. film): $1509,1470\left(-\mathrm{NO}_{2}\right.$ asymm.), 1377, $1282\left(-\mathrm{NO}_{2} \mathrm{symm}\right.$.) $\mathrm{cm}^{-1}$; diisobutylnitramine (If), m.pt. $79-80^{\circ} \mathrm{C}$ (lit. $57,5876-77^{\circ} \mathrm{C}, 81.5-82.5^{\circ} \mathrm{C}$ resp.); ${ }^{1} \mathrm{H} \mathrm{nmr,} \delta: 0.85$ (d,6), 2.20 (sp,1), 3.53 (s,2) ppm; i.r. $v_{\max }$ (mull): 1526, 1492, $1462\left(-\mathrm{NO}_{2}\right.$ asymm.), 1327, $1270\left(-\mathrm{NO}_{2} \mathrm{symm}\right) \mathrm{cm}^{-1} ; \mathrm{N}, \mathrm{N}^{\prime}-$ dinitropiperazine (II), m.pt. $202^{\circ} \mathrm{C}$ (dec.) (lit. ${ }^{58} 215^{\circ} \mathrm{C}$ ); ${ }^{1} \mathrm{H} \mathrm{nmr}, \delta\left(\mathrm{D}_{6}-\mathrm{DMSO}\right): 4.03$ (s) ppm; i.r. $v_{\max }$ (mull): 1545 (-NO 2 asymm.), 1335, 1285, 1241 (-NO2 symm.) cm-1; N,N'-dinitrohexahydropyrimidine (Im), m.pt. $82-83^{\circ} \mathrm{C}$ (lit. $\left.{ }^{28} 84^{\circ} \mathrm{C}\right) ;{ }^{1} \mathrm{H} \mathrm{nmr}, \delta: 1.92(\mathrm{~m}, 2), 3.95(\mathrm{t}, 4), 5.75(\mathrm{~s}, 2) \mathrm{ppm}$; i.r. $v_{\max }$ (mull): $1556,1538\left(-\mathrm{NO}_{2}\right.$ asymm.), $1275\left(-\mathrm{NO}_{2}\right.$ symm.) $\mathrm{cm}^{-1}$.

\section{Preparation of 1-(N,N-dinitramino)propan-2-ol nitrate $(\mathbf{X I})$}

$\mathrm{N}$-(Trimethylsilyl)propyleneimine (VIk) $(2.32 \mathrm{~g}, 18.0 \mathrm{mmol})$ in dichloromethane $(6 \mathrm{ml})$ was added over $12 \mathrm{~min}$. at $-15^{\circ} \mathrm{C}$ to a solution of $\mathrm{N}_{2} \mathrm{O}_{5}(2.0 \mathrm{~g}, 18.5 \mathrm{mmol})$ in the same solvent ( $\left.\mathrm{ca} 10 \mathrm{ml}\right)$. The resulting mixture was stirred for $10 \mathrm{~min}$. whilst allowing to warm to $0^{\circ} \mathrm{C}$ (yellow colour develops), then it was pipetted rapidly into a solution containing excess $\mathrm{N}_{2} \mathrm{O}_{5}(5.0 \mathrm{~g}, 46.3 \mathrm{mmol})$ in dichloromethane $(\mathrm{ca} 15 \mathrm{ml})$ and the mixture was monitored by HPLC (RP18 column, acetonitrile-water $60: 40 \mathrm{v} / \mathrm{v}$ eluant, monitor at $210 \mathrm{~nm}$ ) for disappearance of the $\mathrm{N}$-nitroaziridine. After ca $90 \mathrm{~min}$. at $0 \pm 5^{\circ} \mathrm{C}$ the $\mathrm{N}$-nitroaziridine peak (shortest retention time) had reached a minimum and the peak assigned as the $\mathrm{N}, \mathrm{N}$-dinitramine (longest retention time, $\lambda_{\max } c a$ $240 \mathrm{~nm}$ ) had reached a maximum relative to the propane-1,2-diol dinitrate which was also present in the mixture (intermediate retention time).

The mixture was worked up in the usual manner (wash with saturated sodium bicarbonate solution, dry over anhydrous $\mathrm{MgSO}_{4}$ and evaporate) to give an oil (2.25 g, 62\%) which comprised 1-(N,N-dinitramino)propan-2-ol nitrate (XI), $v_{\max }$ (liquid film) 1647 (-ONO 2 asymm.), 1607 (-N(NO 2$)_{2}$ asymm.), 1274 $\left(-\mathrm{ONO}_{2}\right.$ symm.), $1244\left(-\mathrm{N}\left(\mathrm{NO}_{2}\right)_{2} \mathrm{symm}.\right), 850\left(-\mathrm{ONO}_{2}\right), 815\left(-\mathrm{N}\left(\mathrm{NO}_{2}\right)_{2}\right) \mathrm{cm}^{-1}$ in admixture with propane1,2-diol dinitrate (XII).

\section{Reactions of silylamides VIn-g}

The silylamide $(20 \mathrm{mmol})$ was dissolved in dichloromethane $(10-15 \mathrm{ml})$ and added dropwise with stirring and cooling (at $-5 \pm 2^{\circ} \mathrm{C}$ ) to a solution of $\mathrm{N}_{2} \mathrm{O}_{5}(22 \mathrm{mmol})$ in the same solvent $(20-40 \mathrm{ml})$ [disilylamides VIp and VIq were reacted with $44 \mathrm{mmol}_{2} \mathrm{O}_{5}$ ]. After addition was complete the mixture was stirred for the period shown at the temperature shown in Table 2 . The reaction mixture was then worked up as described above.

Thus prepared were: $\mathrm{N}$-nitro- $\mathrm{N}$-methylacetamide (In), oil, ${ }^{1} \mathrm{H} \mathrm{nmr}, \delta: 2.68(\mathrm{~s}, 3), 3.60(\mathrm{~s}, 3) \mathrm{ppm}$, $\delta\left(\mathrm{CCl}_{4}\right): 2.61(\mathrm{~s}, 3), 3.55(\mathrm{~s}, 3) \mathrm{ppm}\left(\mathrm{lit} .{ }^{34} \delta\left(\mathrm{CCl}_{4}\right): 2.43,3.31 \mathrm{ppm}\right)$; i.r. $v_{\max }$ (liq. film): $1721(\mathrm{CO}), 1569$ ($\mathrm{NO}_{2}$ asymm.), 1239 (-NO $\mathrm{NO}_{2}$ symm.) $\mathrm{cm}^{-1}$ (lit. ${ }^{34} \mathrm{CCl}_{4}$ soln.: 1720, $\left.1575 \mathrm{~cm}^{-1}\right) ; \mathrm{N}$-nitro-1,3-oxazolidin-2-one (Io), m.pt. $106.5-107^{\circ} \mathrm{C}\left(\mathrm{lit} .{ }^{34} 108-109.5^{\circ} \mathrm{C}\right.$ ); ${ }^{1} \mathrm{H} \mathrm{nmr}, \delta: 4.42$ (s) ppm; i.r. $v_{\max }$ (mull): 1786 (CO), 1554 ($\mathrm{NO}_{2}$ asymm.), 1282 (-NO 2 symm.) cm-1; N,N'-dinitro-N-methyl-N'-(n-propyl)urea (Ip), oil, ${ }^{1} \mathrm{H} \mathrm{nmr,} \delta: 0.98$ $(\mathrm{t}, 3), 1.67(\mathrm{~m}, 2), 3.69(\mathrm{~s}, 3), 4.08(\mathrm{t}, 2) \mathrm{ppm}$; i.r. $v_{\max }$ (liq. film): $1723(\mathrm{CO}), 1590\left(-\mathrm{NO}_{2}\right.$ asymm.), $1287\left(-\mathrm{NO}_{2}\right.$ symm.) $\mathrm{cm}^{-1} ; \mathrm{N}, \mathrm{N}^{+}$-dinitro- $\mathrm{N}, \mathrm{N}^{\prime}$-(trimethylene)urea (1,3-dinitro-3,4,5,6-tetrahydro-2(lH)-pyrimidinone, Iq), 
m.pt. $118^{\circ} \mathrm{C}$ (dec.) (lit. $\left.{ }^{36} 121-122^{\circ} \mathrm{C}\right) ;{ }^{1} \mathrm{H} \mathrm{nmr}, \delta: 2.35(\mathrm{~m}, 2), 4.18(\mathrm{t}, 4) \mathrm{ppm}$; i.r. $v_{\max }$ (mull): $1753(\mathrm{CO}), 1571$ $\left(-\mathrm{NO}_{2}\right.$ asymm.), $1266\left(-\mathrm{NO}_{2} \mathrm{symm}\right.$.) $\mathrm{cm}^{-1}$.

\section{Reactions of Silyl Ethers}

The silyl ether ( $20 \mathrm{mmol})$ dissolved in dry dichloromethane ( $c a 10 \mathrm{ml}$ ) was added dropwise over 10 15 min. to a solution of $\mathrm{N}_{2} \mathrm{O}_{5}$ in the same solvent $\left(20-25 \mathrm{ml}\right.$ ). Quantities of $\mathrm{N}_{2} \mathrm{O}_{5}$ used, and temperatures and times of reactions are shown in Table 3. After the appropriate reaction time, the mixture was worked up by washing with saturated sodium hydrogen carbonate solution ( $c a 50 \mathrm{ml}$ ), with addition of further solid sodium hydrogen carbonate if necessary, followed by washing with saturated brine. The organic extract (washed out with further dichloromethane $(15-20 \mathrm{ml})$ ) was then dried over anhydrous magnesium sulphate, and finally the solvent was removed on a Rotavapor to yield the nitrate ester product, which was characterised spectroscopically and, in some cases, by HPLC.

The HPLC analyses employed an internal standard method based on the response of the nitrate ester vs di-(n-pentyl)phthalate. A calibration curve was produced from three different concentrations of an authentic sample of the nitrate ester, and using quadratic curve fitting it was possible to calculate sample purities and hence percentage yields based on the HPLC analyses.

Thus prepared were: 2-ethylhexanol nitrate (XIVa); ${ }^{1} \mathrm{H} \mathrm{nmr,} \delta: 0.90(\mathrm{t}, 6) ; 1.3(\mathrm{~m}, 8) ; 4.30(\mathrm{~d}, 2) ; v_{\max }$ (liq. film) $1632\left(\mathrm{NO}_{2}\right.$ as. $), 1279\left(\mathrm{NO}_{2}\right.$ s. $), 867\left(\mathrm{ONO}_{2}\right.$ gp. $) \mathrm{cm}^{-1} ;$ n-decanol nitrate $(\mathbf{X I V b}) ;{ }^{1} \mathrm{H} \mathrm{nmr}, \delta$ : $0.90(\mathrm{t}, 3) ; 1.3$ (brs, 16$) ; 4.45(\mathrm{t}, 2)$; $v_{\max }$ (lig. film) $1632\left(\mathrm{NO}_{2}\right.$ as. $), 1280\left(\mathrm{NO}_{2} \mathrm{~s}\right.$.), $864\left(\mathrm{ONO}_{2} \mathrm{gp}\right) \mathrm{cm}^{-1} ; 2$ octanol nitrate (XIVc); ${ }^{1} \mathrm{H} \mathrm{nmr}, \delta: 0.80(\mathrm{~m}, 3) ; 1.35(\mathrm{~m}, 13) ; 5.05(\mathrm{qr}, 1) ; v_{\max }$ (liq. film) $1625\left(\mathrm{NO}_{2}\right.$ as.), 1279( $\mathrm{NO}_{2}$ s.), 876(ONO${ }_{2}$ gp.) $\mathrm{cm}^{-1}$; hexane-1,6-diol dinitrate (XIVd); ${ }^{1} \mathrm{H} \mathrm{nmr}, \delta: 0.15(\mathrm{~s}, 18) ; 1.45(\mathrm{~m}, 8)$; $3.60(\mathrm{t}, 4) ; v_{\text {max }}$ (liq. film) $1632\left(\mathrm{NO}_{2}\right.$ as.), $1280\left(\mathrm{NO}_{2} \mathrm{~s}\right.$ ), $872\left(\mathrm{ONO}_{2} \mathrm{gp}\right.$.) $\mathrm{cm}^{-1} ; 2,2$-(pentamethylene)propane1,3-diol dinitrate (XIVe); ${ }^{1} \mathrm{H} \mathrm{nmr}, \delta$ : 1.53 (br.s, 10); 4.43(s,4); $v_{\max }$ (liq. film) $1638\left(\mathrm{NO}_{2}\right.$ as.), $1277\left(\mathrm{NO}_{2} \mathrm{~s}\right.$.), $867\left(\mathrm{ONO}_{2}\right.$ gp.) $\mathrm{cm}^{-1} ; 3,3-$ bis(nitratomethyl)oxetane (XIVf); ${ }^{1} \mathrm{H} \mathrm{nmr}, \delta: 4.65(\mathrm{~s}, 4) ; 4.85(\mathrm{~s}, 4) ; v_{\max }$ (liq. film) 1644, 1278, $867 \mathrm{~cm}^{-1}$; DINA (XVIII); ${ }^{1} \mathrm{H} \mathrm{nmr}, \delta: 4.13(\mathrm{t}, 4) ; 4.76(\mathrm{t}, 4) ; v_{\max }$ (mull) $1638\left(\mathrm{NO}_{2}\right.$ as., n.ester), 1523( $\mathrm{NO}_{2}$ as., nitramine), $1283\left(\mathrm{NO}_{2}\right.$ s.) $\mathrm{cm}^{-1}: 2,2$-dimethylpropane-1,3-diol dinitrate $(\mathbf{X X I}) ;{ }^{1} \mathrm{H} \mathrm{nmr}, \delta$ : $1.10(\mathrm{~s}, 6) ; 4.28(\mathrm{~s}, 4) ; v_{\max }$ (liq. film) $1636\left(\mathrm{NO}_{2}\right.$ as.), $1278\left(\mathrm{NO}_{2} \mathrm{~s}.\right), 866\left(\mathrm{ONO}_{2} \mathrm{gp}\right.$.) $\mathrm{cm}^{-1}$; silyl nitrate (XXII); ${ }^{1} \mathrm{H} \mathrm{nmr}, \delta: 0.05(\mathrm{~s}, 6) ; 0.95(\mathrm{~s}, 6) ; 3.40(\mathrm{~d}, 2) ; 4.28(\mathrm{~d}, 2) ; v_{\max }$ (liq. film) $1632\left(\mathrm{NO}_{2}\right.$ as. $), 1279\left(\mathrm{NO}_{2} \mathrm{~s}\right.$ ); $1263\left(\mathrm{NO}_{2}\right.$ s.), 872, $808\left(\mathrm{ONO}_{2}\right.$ gp.) cm-1; butane-1,2-diol dinitrate (XXIII); ${ }^{1} \mathrm{H} \mathrm{nmr}, \delta: 0.5-0.8(\mathrm{~m}, 2) ; 1.0(\mathrm{~m}, 3) ; 4.3(\mathrm{~m}, 2)$; $4.5(\mathrm{~m}, 1) ; v_{\max }$ (liq. film) $1640\left(\mathrm{NO}_{2}\right.$ as.), $1270\left(\mathrm{NO}_{2} \mathrm{~s}\right.$.) $\mathrm{cm}^{-1}$.

In the case of one trimethylsilyl ether (XIIIa), the formation of trimethylsilyl nitrate (VIIa) as a byproduct and its partial recovery were demonstrated as follows:- the reaction was carried out as described above, except in $\mathrm{CDCl}_{3}$ instead of $\mathrm{CH}_{2} \mathrm{Cl}_{2}$. The reaction mixture, prior to the sodium hydrogen carbonate quench, was examined by solution i.r. $\left(\mathrm{CDCl}_{3}\right)$ and an additional nitrate ester peak was observed at 1602 $\mathrm{cm}^{-1}$. The $\mathrm{CDCl}_{3}$ was carefully distilled off on a Rotavapor, ensuring that the vacuum did not exceed 150 $\mathrm{mm}$ (water bath temp. $40^{\circ} \mathrm{C}$ ). The distillate was examined by solution i.r. and HPLC (RP1 8 column, 50:50 $\mathrm{MeCN}$-water), which showed that a small amount of VIIa had been evaporated off; distillation of the product mixture on a GKR at $150 \mathrm{~mm}$ and $80^{\circ} \mathrm{C}$ yielded further VIIa as a colourless liquid, $v_{\max }\left(\mathrm{CDCl}_{3}\right.$ soln.) 1600 $\left(\mathrm{NO}_{2}\right.$ as.), $1295\left(\mathrm{NO}_{2}\right.$ s. $) \mathrm{cm}^{-1}$; lit. ${ }^{40 \mathrm{~b}} v_{\max }$ (liq. film) $1600\left(\mathrm{NO}_{2}\right.$ as. $), 1300\left(\mathrm{NO}_{2}\right.$ s.), which had a HPLC retention time identical to that of an authentic sample prepared as described in the literature ${ }^{40 b}$. Approximately $40 \%$ of the theoretical amount of trimethylsilyl nitrate was recovered in this way. 


\section{REFERENCES AND NOTES}

1. Part 10 of "Nitration by Oxides of Nitrogen"; Part 9: Golding, P.; Millar, R. W.; Paul, N. C.; Richards, D. H., "Preparation of Nitramine-Nitrates by Ring-Opening Nitration of Azetidines by Dinitrogen Pentoxide $\left(\mathrm{N}_{2} \mathrm{O}_{5}\right)^{\prime \prime}$, Tetrahedron, 1995, 51(17), 5073-5082.

2. Presented in part at 209th A.C.S. National Meeting, Anaheim, Calif., 2-5 April 1995 and 27th Internat. Ann. Conf. of I.C.T. on Energetic Materials, Karlsruhe, Germany 25-28 June 1996.

3. Urbanski, T., Chemistry and Technology of Explosives, 3, Pergamon Press, Oxford (1967).

4. See ref. 3 , Vol. 2 .

5. Grayson, M. (Ed.) Kirk-Othmer Encyclopedia of Chemical Technology, 3rd Edition, 9, pp 572-581, Wiley-Interscience, New York, 1980.

6. See ref. 5 , Vol. 11, p. 929.

7. Shiratsuchi, M.; Kawamura, K.; Akashi, T.; Fujii, M.; Ishihama, H.; Uchida, Y., Chem. Pharm. Bull., 1987, 35, 632-641 and refs. contained therein.

8. a) Wright, G. F., "Methods of Formation of the Nitramino Group, its Properties and Reactions" in Feuer, H. (Ed.) The Chemistry of the Nitro and Nitroso Groups, (The Chemistry of Functional Groups Series, Patai, S., Series Ed.), Part 1, Ch. 9, Interscience, New York, 1969; b) Smith, P. A. S., Open Chain Nitrogen Compounds, 2, 503, Benjamin, New York 1966; c) Coombes, R. G., "Nitro and Nitroso Compounds" in Sutherland I. O. (Ed.) Comprehensive Organic Chemistry, Barton, D.; Ollis W. D. (Series Eds.), 2, Pergamon, Oxford, 1979; d) Fischer, J. W. "The Chemistry of Dinitrogen Pentoxide" in Feuer, H.; Nielsen, A. T. (Series Eds.) Nitro Compounds: Recent Advances in Synthesis \& Chemistry (Organic Nitro Chemistry Series), Ch. 3, pp. 338-346, VCH, New York, 1990.

9. a) Boschan, R.; Merrow, R. T.; van Dolah, R. W., Chem. Rev. 1955, 55, 485-510; b) Olah, G. A.; Malhotra, R.; Narang, S. C., Nitration, Methods and Mechanisms, pp. 269-75, VCH, New York, 1989; c) Olah, G. A. "Methods for Preparing Energetic Nitrocompounds" in Olah, G. A.; Squire, D. R. (Eds.) Chemistry of Energetic Materials, Ch. 7, pp 186-191, Academic Press, San Diego \& London, 1991. See also ref. $8 \mathrm{~b}$ and ref. $8 \mathrm{~d}$, pp. $327-330$.

10. See ref. 3 , pp. 8-13.

11. Chute, W. J.; Herring, K. G.; Tombs L. E.; Wright, G. F., Canad. J Res., 1948 26B, 89-103.

12. Emmons, W. D.; Pagano, A. S.; Stevens, T. E., J Org. Chem., 1958 23, 311-3; see also ref. 8d.

13. Chapman, F., J Chem. Soc., 19491631.

14. For further details, see a) ref. 3 , b) ref. $8 \mathrm{c}$.

15. Andreev, S. A.; Novik, L. A.; Lebedeev, B. A.; Tselinskii, I. V.; Gidaspov, B. V., J. Org. Chem. USSR, $197814(2), 221-4$.

16. Cichra, D. A.; Adolph, H. G., J Org. Chem., 1982 47(12), 2474-6.

17. Boyer, J. H.; Pillai, T. P.; Ramakrishnan, V. T., Synthesis, 1985 677-9.

18. For detailed discussion of this problem see: Bottaro, J. C.; Schmitt, R. J.; Bedford, C. D., J. Org. Chem., $198752(11), 2292-4$.

19. Siele, V. I.; Warman, M.; Leccacorvi, J.; Hutchinson, R. W.; Motto, R.; Gilbert, E. E.; Benzinger, T. M.; Coburn, M. D.; Rohwer, R. K.; Davey, R. K., Propellants \& Explosives, 1981 6, 67-73.

20. See ref. 8 c, p. 371.

21. Koppes, W. M.; Chaykovsky, M.; Adolph, H. G., J Org. Chem., 1987 52(6), 1113-9.

22. See ref. 4 , p. 155 .

23. Paul, N. C., DRA, personal communication.

24. Castedo, L.; Marcos, C. F.; Monteagudo, M.; Tojo, G., Synth. Commun., 1992 22(5), 677-681.

25. Olah, G. A.; Wang, Q.; Li, X.; Prakash, G. K. S., Synthesis, 1993(2), 207-208.

26. Nielsen, A. T., N.A.W.C. China Lake, Calif., personal communication.

27. a) Schmitt, R. J.; Bottaro, J. C.; Malhotra, R.; Bedford, C. D., J Org. Chem., 1987 52(11), 2294-7; b) 
Olah, G. A.; Rochin, C., J. Org. Chem., 1987 52, 701-702; c) ref. 9b, Ch. 4.

28. Willer, R. L.; Atkins, R. L., J Org. Chem., 1984 49, 5147-50.

29. Scherer, O. J.; Schmidt, M., Chem. Ber., 1965 98, 2243.

30. Aerojet-General Corp., Brit. Pat. 1126591(6/9/63).

31. First synthesised in 1977: Haire, M. J.; Boswell, G. A., J Org. Chem., 1977 42, 4251-6; Haire, M. J.; Harlow, R. L., J Org. Chem., 1980 45, 2264-5.

32. Golding, P.; Millar, R. W.; Paul, N. C.; Richards, D. H., Tetrahedron Lett., 1991 32(37), 4985.

33. Coon, C. L., L.L.N.L. Livermore, Calif., personal communication.

34. White, E. H.; Chen, M. C.; Dolak, L. A., J Org. Chem., 1966 31, 3038-46.

35. Roesky, H. W.; Lucas, J., Inorg. Synth., 1986 24, 120-1.

36. McKay, A. F.; Wright, G. F., J Am. Chem. Soc., 1948 70, 3990-4.

37. E. W. Colvin, Silicon Reagents in Organic Synthesis, p. 91, Academic Press, London, 1988.

38. Golding, P.; Millar, R. W.; Paul, N. C.; Richards, D. H., Tetrahedron, 1993 49(32), 7063-7076.

39. Voronkov, M. G.; Romadane, P., Khim. Geterot. Soed., 1966(6), 879-91; Chem. Abs. 1967 67, $32775 f$.

40. a) Hardinger, S. A.; Wijaya, N., Tetrahedron Lett., 1993 34(24), 3821-3824; b) Kimura, M.; Kajita, K.; Onoda, N.; Morosawa, S., J Org. Chem., 1990 55, 4887-4892.

41. During the course of this work the nitrodesilylation of a few aliphatic secondary silylamines by nitronium tetrafluoroborate was noted (i) ref. 9c, Ch. 7, p.197; ii) Dave, P. R.; Farhad, F.; Axenrod, T.; Bedford, C. D.; Chaykovsky, M.; Rho, M.-K.; Gilardi, R.; George, C., Phosphorus, Sulfur, Silicon Relat. Elem., 199490 (1-4), 175-184], but the necessity of using nitronium tetrafluoroborate reduces the scale-up potential of these reactions. Some mention has also been made of the formation of $\mathrm{N}$-nitroheteroaromatics by the reaction of the corresponding $\mathrm{N}$-silyl compounds with $\mathrm{NO}_{2} \mathrm{BF}_{4}$ (Glass, R. S. et al., Canad. J. Chem., 1972 50, 3472-7) but the products are principally of use as transfer nitrating reagents. Additionally, a limited investigation of the reactions of some simple silylamines with $\mathrm{N}_{2} \mathrm{O}_{5}$ was reported but did not result in a general nitramine synthesis (Schultheiss, H.; Fluck, E., Z. Anorg. Allg. Chem., 1978 445, 20-26). Hence it is concluded that the formation of $\mathrm{N}$-nitro derivatives of dialkyl- and cycloalkylamines, as a general reaction using $\mathrm{N}_{2} \mathrm{O}_{5}$ constitutes a novel synthesis of these classes of compounds.

42. Moodie, R. B., University of Exeter, personal communication.

43. See ref. 9 b, p. 42.

44. E.g. see Clark, J. H. (Ed.), Chemistry of Waste Minimisation, Chapman \& Hall, London, 1995.

45. Breed, L. W.; Haggerty, W. J.; Harvey, J., J Org. Chem., 1960 25, 1804-6.

46. Kakimoto, M. A.; Oishi, Y.; Imai, Y., Makromol. Chem. Rapid Commun., 1985 6, 557-62.

47. Rauchschwalbe, G.; Ahlbrechte, H., Synthesis, 1974 9, 663-5.

48. Sundberg, R. J.; Russell, H. F., J Org. Chem., 1973 38, 3324-330.

49. Titherley, A. W.; Branch, G. E. K., J Chem. Soc., 1913330.

50. Birkhofer, L.; Kühlthau, H. P.; Ritter, A., Chem. Ber., 1960 93, 2810-3.

51. Ishihara, K.; Kurihara, H.; Yamamoto, H., J Org. Chem., 1993 58, 3791-3.

52. Backer, H. J.; Winter, H. J., Rec. Trav. Chim. Pays-Bas, 1937 56, $492-509$.

53. Pattison, D. B., J Am. Chem. Soc. 1957 79, 3455.

54. Harris, A. D.; Trebellas, J. C.; Jonassen, H. B., Inorg. Synth., 1967 9, 83-88.

55. Suri, S. C.; Chapman, R. D., Synthesis, 1988, 743-5.

56. Lamberton, A. H., Q. Rev., 1951 5, 75-98.

57. Luk'yanov, O. A.; Seregina N. M.; Tartakovskii, V. A., Bull. Acad. Sci. USSR Chem. Ser., 1976 (1), 220 1; Chem. Abs. 197684135574.

58. Robson, J. H.; Reinhart, J., J Am. Chem. Soc., 1955 77, 2453-7.

(C) British Crown Copyright 1996/ DRA Farnborough Hants. U.K.

Published with the permission of the Controller of Her Britannic Majesty's Stationery Office. 